\title{
Prevalence of metabolic syndrome among patients with Schizophrenia in Palestine
}

\author{
Waleed M Sweileh*, Sa'ed H Zyoud, Salah A Dalal, Sami Ibwini, Ansam F Sawalha and lyad Ali
}

\begin{abstract}
Background: Metabolic syndrome (MS) is a cluster of the most dangerous cardiac risk factors and is associated with high mortality. Ethnic differences in metabolic syndrome (MS) criteria and prevalence rates have been reported. The purpose of this study was to investigate the MS prevalence among patients with schizophrenia in Palestine.

Methods: We recruited 250 patients with schizophrenia from 4 psychiatric primary healthcare centers in Northern Palestine. The MS prevalence was assessed based on National Cholesterol Education Program Adult Treatment Panel III Adapted criteria.

Results: The overall MS prevalence was 43.6\%, with 39\% in male and $55.9 \%$ in female patients. On average, the study patients had $2.3 \pm 1.3$ metabolic abnormalities. Univariate analysis showed that MS was significantly higher with older age, female gender, longer duration of the illness, smoking, abdominal obesity, high systolic and diastolic blood pressure, high triglycerides, low HDL-C, and high fasting plasma glucose. Multiple logistic regression analysis showed that only systolic blood pressure, high triglycerides, high fasting plasma glucose, and low HDL-C were significant predictors of MS in schizophrenic patients.
\end{abstract}

Conclusions: MS is common among Arab patients with schizophrenia. Patients with schizophrenia should receive regular monitoring and adequate treatment of cardio-metabolic risk factors.

Keywords: Schizophrenia, Metabolic syndrome, Palestine

\section{Background}

Schizophrenia is a mental disorder that affects approximately one percent of the various populations throughout the world [1-3]. Patients with schizophrenia are reported to have shorter life span compared to the general population [4-6]. The most commonly reported cause of excess mortality among patients with schizophrenia is cardiovascular diseases [7,8]. Cardiovascular morbidity and mortality among patients with schizophrenia has been linked to high prevalence of metabolic syndrome [9]. Metabolic syndrome (MS), also known as syndrome $\mathrm{X}$ or insulin resistance syndrome is a cluster of interrelated metabolic risk factors that appear to directly promote the development of atherosclerotic cardiovascular disease [10-13]. Furthermore, metabolic abnormalities not only have an impact on physical health

\footnotetext{
* Correspondence: waleedsweileh@yahoo.com

College of Medicine and Health Sciences, Division of Pharmacy An-Najah National University, Nablus, Palestine
}

but also on a poorer quality of life [14], non-compliance [15] and a lower functional outcome [16].

Three definitions of MS have been proposed by the National Cholesterol Education Program Adult Treatment Panel III (NCEP ATPIII), the World Health Organization (WHO) and the International Diabetes Federation (IDF) [17-19]. Regardless of the criteria, five factors, are thought to comprise MS-large waist circumference (WC; as indicator of central obesity), elevated triglycerides (TG), low high-density lipoprotein cholesterol (HDL-C) concentration, high blood pressure and elevated fasting plasma glucose. The most commonly used definitions for the MS are the NCEP ATPIII, and the adapted ATP-III A proposed by the American Heart Association (AHA) following the ADA lowering of the threshold for impaired fasting glucose to $100 \mathrm{mg} /$ dl $[20,21]$. The IDF stressed the importance of waist circumference, using both more stringent and ethnic-/ race-specific criteria in the definition of MS. Recently, 
IDF and American Heart Association (AHA) and the National Heart, Lung, and Blood Institute (NHLBI) representatives held discussions to attempt to resolve the remaining differences between definitions of metabolic syndrome. Both sides agreed that abdominal obesity should not be a prerequisite for diagnosis but that it is 1 of 5 criteria, so that the presence of any 3 of 5 risk factors constitutes a diagnosis of metabolic syndrome [22].

Recent research on MS in the general population has indeed provided evidence for the development of ethnic-/race-specific criteria [23-25]. Until now, it has remained unclear to what extent these differences in the general population are due to genetic factors or cultural factors such as life style or economic factors. As the criteria of MS as well as life style and economic factors are different between ethnic groups, evaluation of the prevalence of MS in patients with schizophrenia in different ethnic groups is needed.

Many reports have been published on the prevalence of the MS in the general population among Arabs in the Middle East [26-28]. However, reports about the prevalence of MS among Arab patients with schizophrenia are very few. To further investigate the prevalence of metabolic syndrome among Arab patients with schizophrenia, this study was carried out among a sample of patients with schizophrenia in Palestine.

\section{Methods}

\section{Research design and methods}

This is a cross sectional study conducted from August 2011 until February 2012 at governmental primary healthcare psychiatric centers in Northern West-Bank, Palestine. All patients attending the psychiatric healthcare centers during the study period with the following criteria were invited to participate: 1) their age was above 16 years old, and 2) they were diagnosed with schizophrenia as defined by DSM-IV. In order to estimate with sufficient precision the prevalence of MS, we hypothesized that the prevalence of MS to be $30 \%$. We calculated the sample size with a $99 \%$ confidence interval and of a $10 \%$ width. Based on this, we needed a sample size at least 100 patients.

On the assessment day, we collected demographic and clinical information, including current antipsychotic use, from medical documents of the institutions. The following types of information were collected: gender, age, occupation, marital status, length of psychiatric illness, antipsychotic medications; waist circumference (WC), fasting plasma glucose (FPG) measured in $\mathrm{mg} / \mathrm{dL}$, and lipid profile. Focus group discussions were continuously held between the research team to maintain rational of the data collection process. Regular evaluations took place throughout the abstraction period to identify any problems in data collection, the interpretation of definitions, and the application of study criteria. Before commencing data analysis, an extensive series of checks were performed for data consistency, proper sequences of data, and an evaluation of missing or incomplete data. The data collection form was modified by the principal researchers and the modified version was reviewed by experts to ensure content and construct validity. Data from the pre-test evaluation were not included in the final analysis. Approval to perform the study was obtained from the Palestinian ministry of health and the college of Graduate Studies at An-Najah national University and Institutional Review Board (IRB). Written consent was obtained from patients.

The antipsychotic use patterns were recorded by the types and number of administered antipsychotic drugs. As clozapine and olanzapine have the highest potential to cause metabolic abnormalities [29,30] and weight gain [31], we classified the types of antipsychotic drugs into a clozapine/ olanzapine group and other antipsychotics group. The number of antipsychotics used was categorized as monotherapy, currently using only one kind of antipsychotic drug, and combination, currently using more than one kind of antipsychotic. Medical information regarding the duration of current antipsychotic regimen or previous antipsychotic usage were not obtained due to limited related information in their documents. Waist circumference (WC) was measured using an outstretched tape meter, without any pressure to the body surface, and was recorded to the nearest $0.1 \mathrm{~cm}$. The waist measurement was taken with the tape meter in a horizontal plane, midway between the inferior margin of the ribs and the superior border of the iliac crest. To avoid inter-subjective error, all measurements were taken by the same person. Sitting blood pressure (BP) was performed. Two BP measurements were made by two nurses in the right arm after the participant sat and rested for at least $5 \mathrm{~min}$. In case of difference in BP reading, a third one was carried out and the average was calculated. For FPG blood samples were collected from all subjects between 8:00 and 9:00 (a.m.) after $12 \mathrm{~h}$ overnight fast. Blood was collected from an ante-cubital vein punctures and was collected while subject or client in a sitting position. FPG was determined using Chemistry kits bought from Human, Germany. Blood samples were taken in a sitting position according to the standard protocol and centrifuged within 30 to 45 minutes of collection. Biochemical analysis was conducted on fasting plasma samples; all blood analyses being done at the University laboratory on the day of blood collection. For lipid measurement, LDL-C, HDL-C, $\mathrm{TC}$, and TG were measured using HUMAN kit, Germany. The MS was defined according to ATPIII definition.

Chlorpromazine equivalents (CPZeq): Total CPZeq was constructed by calculating a total daily dose of each 
Table 1 General characteristics of the study sample

\begin{tabular}{|c|c|c|c|c|c|}
\hline \multirow[b]{2}{*}{ Variable } & \multicolumn{3}{|c|}{$N(\%)$ or Mean \pm SD } & \multirow{2}{*}{$\begin{array}{l}\text { P value d } \\
\text { (Cohen's } \\
\text { value) and/ } \\
\text { or OR (95Cl) }\end{array}$} & \multirow{2}{*}{$\begin{array}{c}\text { Chi- } \\
\text { Square } \\
\text { value } \\
\left(X^{2}\right) \text { Or } \\
t \text {-test } \\
\text { value }\end{array}$} \\
\hline & $\begin{array}{c}\text { Total } \\
250(100 \%)\end{array}$ & $\begin{array}{c}\text { Male } \\
182(73.8 \%)\end{array}$ & $\begin{array}{c}\text { Female } \\
68(27.2 \%)\end{array}$ & & \\
\hline \multirow[t]{2}{*}{ Age (years) } & $41.9 \pm 11.8$ & $42.5 \pm 11.5$ & $40.3 \pm 12.4$ & $0.2^{a}$ & \\
\hline & & & & $d=0.18$ & -1.3 \\
\hline Education & & & & $0.4^{\mathrm{b}}$ & \\
\hline$\leq$ School education & $213(85.2 \%)$ & $153(84.1)$ & $60(88.2)$ & $1.4(0.62-3.3)$ & \\
\hline College education & $37(14.8 \%)$ & $29(15.9)$ & $8(11.8)$ & $d=0.18$ & 0.68 \\
\hline Marital Status & & & & $<0.01^{b}$ & \\
\hline Married & $138(55.2 \%)$ & $88(48.4)$ & $50(73.5)$ & $3(1.6-5.5)$ & \\
\hline Single/Divorced & $112(44.8 \%)$ & $94(51.6)$ & $18(26.5)$ & $d=0.61$ & 12.7 \\
\hline Smoker & & & & $<0.01^{b}$ & \\
\hline Yes & $153(61.2 \%)$ & $55(80.9)$ & $42(23.1)$ & $14.1(7-28.3)$ & \\
\hline No & 97 (38.8\%) & $13(19.1)$ & $140(76.9)$ & $d=1.46$ & 69.66 \\
\hline Occupation & & & & $0.1^{\mathrm{b}}$ & \\
\hline Not working & $219(87.6 \%)$ & $156(85.7)$ & $63(92.6)$ & $2.1(0.8-5.7)$ & \\
\hline Working & $31(12.4 \%)$ & $26(14.3)$ & $5(7.4)$ & $d=0.41$ & 2.2 \\
\hline \multirow[t]{2}{*}{ Duration of psychiatric illness } & $15.8 \pm 9.3$ & $16.2 \pm 9.0$ & $14.8 \pm 9.9$ & $0.3^{\mathrm{a}}$ & \\
\hline & & & & $d=0.15$ & -1.01 \\
\hline Waist Circumference & & & & $<0.01^{\mathrm{b}}$ & \\
\hline Normal & $137(54.4)$ & $124(68.1 \%)$ & $12(17.6 \%)$ & $0.1(0.05-0.2)$ & \\
\hline Above Normal & $114(45.6 \%)$ & $58(31.9 \%)$ & $56(82.4 \%)$ & $d=-1.27$ & 50.86 \\
\hline \multirow[t]{2}{*}{ Systolic Blood Pressure } & $124.2 \pm 14.4$ & $125.1 \pm 14.1$ & $121.8 \pm 15$ & $0.1^{\mathrm{a}}$ & -1.6 \\
\hline & & & & $d=0.23$ & \\
\hline \multirow[t]{2}{*}{ Diastolic Blood Pressure } & $75.5 \pm 10.8$ & $76.4 \pm 10.2$ & $73 \pm 12.1$ & $0.04^{a}$ & -2.0 \\
\hline & & & & $d=0.3$ & \\
\hline \multirow[t]{2}{*}{ Triglycerides } & $193.2 \pm 180.2$ & $187.3 \pm 125.4$ & $208.8 \pm 279$ & $0.5^{\mathrm{a}}$ & 0.6 \\
\hline & & & & $d=-0.1$ & \\
\hline \multirow[t]{2}{*}{ HDL-C } & $44.9 \pm 10.9$ & $43.8 \pm 11$ & $46.4 \pm 10.6$ & $0.1^{\mathrm{a}}$ & 1.7 \\
\hline & & & & $d=-0.24$ & \\
\hline \multirow[t]{2}{*}{ FPG } & $99.5 \pm 47.5$ & $96.6 \pm 45.3$ & $107.3 \pm 52.6$ & $0.1^{\mathrm{a}}$ & 1.5 \\
\hline & & & & $d=-0.2$ & \\
\hline \multirow[t]{2}{*}{ CPZeq } & $436.9 \pm 275.6$ & $455.6 \pm 283.7$ & $386.8 \pm 247.7$ & $0.07^{a}$ & -1.9 \\
\hline & & & & $d=0.3$ & \\
\hline Olanzapine/Clozapine & & & & $0.9^{b}$ & \\
\hline Yes & $30(12)$ & $22(12.1)$ & $8(11.8)$ & $1.2(0.6-2.3)$ & 0.18 \\
\hline No & $220(88)$ & $160(87.9)$ & $60(88.2)$ & $d=0.1$ & \\
\hline Drug regimen & & & & $0.1^{b}$ & \\
\hline Monotherapy & $124(49.6)$ & $85(46.7)$ & $39(57.4)$ & $1.5(0.9-2.7)$ & 2.2 \\
\hline Combination therapy & $126(50.4)$ & $97(53.3)$ & $29(42.6)$ & $d=0.22$ & \\
\hline
\end{tabular}

Abbreviations: SD, Standard deviation; OR, Odds ratio; $C l$, confidence interval; HDL-C, High-density lipoprotein cholesterol; FPG, Fasting plasma glucose; $C P Z e q$, Chlorpromazine equivalents.

${ }^{a}$ Statistical significance of differences estimated with the independent Student's $t$ test.

${ }^{b}$ Statistical significance of differences estimated with the Chi square test. 
antipsychotic listed in the medical file. Then each converted antipsychotic-specific CPZeq amount is added to arrive at a total dose. The daily dose of antipsychotic medication prescribed to each patient was converted to milligram equivalents of chlorpromazine according to conversion factors derived from the literature [32-34].

The operational definition of antipsychotic combination is the use of two or more antipsychotic drugs while that of monotherapy is the use of one antipsychotic drug.

\section{Statistical analysis}

Descriptive statistics for all study variables were computed. These descriptive statistics included frequencies and percentages for all categorical variables in addition to means, standard deviations and ranges for all normally distributed continuous variables while median and inter quartile range was used for continuous variables that were not normally distributed. Differences between groups were carried out using independent sample $t$ test for continuous variable while Chi-square test was used for categorical variables. The size effect for continuous variables was expressed as Cohen's $d$ value using the on line calculator (http://www.uccs.edu/ lbecker/). For categorical variables, the size effect was calculated as OR and then converted to Cohen's d value based on mathematical equation present in literature [35]. Univariate analysis was carried out using the Binary logistic regression while multiple logistic regression was carried out on variables that showed significance in univariate analysis. In both univariate and multiple logistic regression, the presence of MS was used as the dependent categorical variable. All statistical analyses were conducted using Statistical Package for Social Sciences SPSS (PASW version 18.0; IBM, Somers, NY) statistical packages for Windows. The conventional 5 percent significance level was used throughout the study.

\section{Results}

\section{General descriptive data}

A total of 250 patients diagnosed with schizophrenia were recruited for this study. Mean age of the patients was $41.9 \pm 11.8$ [95\% CI: $40.5-43.4$ ] years. No significant difference in age was found between male and female patients $(40.3 \pm 12.4$ for females versus $42.5 \pm$ 11.5 years for males; $p=0.2$ ). The median duration of the psychiatric illness was $15(\mathrm{Q} 1-\mathrm{Q} 3: 9-20)$ years. The majority $(194,77.6 \%)$ of the patients were using first-generation antipsychotic (FGA) while $33(13.2 \%)$ were using second-generation antipsychotics (SGA) and $23(9.2 \%)$ were using both FGA and SGA. Table 1 shows the general characteristics of the sample stratified with gender.

The most common antipsychotic medication used by the patients was chloropromazine tablet $(128 ; 31.5 \%)$, followed by fluphenazine IM depot injection (125; 30.8\%), haloperidol tablet $(74 ; 18.2 \%)$, clozapine $(35,8.6 \%)$, olanzapine $(15,3.7 \%)$, haloperidol decanoate $(11,2.7 \%)$, risperidone $(8,2 \%)$, trifluperazine $(7,1.7 \%)$, thioridazine $(1,0.2 \%)$ and zuclopenthixol $(2,0.5 \%)$. Table 1 shows the demographic and clinical characteristics of the participants.

\section{Prevalence of metabolic syndrome}

According to the ATP-III A criteria: 109 (43.6\%) patients met the criteria for the syndrome (3 or more MS criteria) while141 (56.4\%) patients did not meet the full criteria for the syndrome (2 or less MS criteria); (Table 2). On average, the study patients had $2.3 \pm 1.3$ metabolic abnormalities. Table 3 displays the distribution of metabolic components as defined by ATP-III A criteria among the recruited patients. Among males, high TG was the most common metabolic component while abdominal obesity was the most common among females (Table 4). High FPG was the least common metabolic dysregulation in both genders.

The frequency of abdominal obesity (WC) and low HDL-C in female patients was significantly higher than that in males. The overall prevalence of MS was $43.6 \%$. Female patients had higher MS prevalence than male patients.

\section{Univariate analysis and logistic regression}

Univariate analysis (Table 3) shows that cases with MS were significantly older, being females, having longer duration of the illness, smokers, had higher systolic and diastolic BP, higher waist circumference, higher TG, FPG, and lower HDL compared to cases without MS. Borderline significance was found between cases with and without MS with regard to using depot antipsychotic medications and LDL level. On the other hand there was no significant difference between both groups with regard to other variables. Multiple logistic regression (Table 3) which included significant variables in univariate analysis indicated that SBP, TG, FPG, HDL and $\mathrm{WC}$ were significantly associated with MS cases.

Table 2 Prevalence of metabolic abnormalities using ATPIII a criteria among 250 patients with schizophrenia in Northern Palestine

\begin{tabular}{cccc}
\hline \multirow{2}{*}{$\begin{array}{c}\text { Number of MS } \\
\text { criteria }\end{array}$} & N (\%) & \multicolumn{2}{c}{ Gender } \\
\cline { 3 - 4 } & & Male & Female \\
\hline 0 & $22(8.8 \%)$ & $21(11.5 \%)$ & $1(1.5 \%)$ \\
1 & $56(22.4 \%)$ & $46(25.3 \%)$ & $10(14.7 \%)$ \\
2 & $63(25.2 \%)$ & $44(24.2 \%)$ & $19(27.9 \%)$ \\
3 & $52(20.8 \%)$ & $38(20.9 \%)$ & $14(20.6 \%)$ \\
4 & $47(18.8 \%)$ & $28(15.4 \%)$ & $19(27.9 \%)$ \\
5 & $10(4 \%)$ & $5(2.7 \%)$ & $5(7.4 \%)$ \\
$M S \geq 3$ & $109(43.6 \%)$ & $71(39 \%)$ & $38(55.9 \%)$ \\
\hline
\end{tabular}


Table 3 Univariate and logistic regression analysis of metabolic syndrome of $\mathbf{2 5 0}$ patients

\begin{tabular}{|c|c|c|c|c|}
\hline Variable & $\begin{array}{c}\text { With MS N } \\
\text { (\%) or Mean } \pm \text { SD }\end{array}$ & $\begin{array}{l}\text { Without MS } N(\%) \\
\text { or Mean } \pm \text { SD }\end{array}$ & $\begin{array}{l}\text { Unadjusted OR } \\
(95 \% \mathrm{Cl})\end{array}$ & $\begin{array}{l}\text { Adjusted OR } \\
(95 \% \mathrm{Cl})\end{array}$ \\
\hline Age (years) & $45.1 \pm 10.4$ & $39.5 \pm 12.2$ & $1.04(1.02-1.07)$ & $0.98(0.93-1.03)$ \\
\hline \multicolumn{5}{|l|}{ Gender } \\
\hline Female & 38 (55.9\%) & $30(44.1 \%)$ & $2(1.1-3.5)$ & $1.91(0.64-5.69)$ \\
\hline Male & $71(39 \%)$ & $111(61 \%)$ & & \\
\hline \multicolumn{5}{|l|}{ Duration } \\
\hline$<10$ years & 90 (42.3\%) & $123(57.7 \%)$ & $2.2(1.3-3.8)$ & $1.94(0.62-6.01)$ \\
\hline$>10$ years & $19(51.4)$ & $18(48.6 \%)$ & & \\
\hline \multicolumn{5}{|l|}{ Smoking } \\
\hline Yes & 55 (35.1\%) & 98 (64.9\%) & $2.2(1.3-3.8)$ & $2.16(0.82-5.69)$ \\
\hline No & $54(55.7 \%)$ & $43(44.3 \%)$ & & \\
\hline \multicolumn{5}{|l|}{ Marital status } \\
\hline Married & $53(47.3 \%)$ & $59(52.7 \%)$ & $0.76(0.46-1.25)$ & - \\
\hline Single & $56(40.6 \%)$ & $82(59.4 \%)$ & & \\
\hline \multicolumn{5}{|l|}{ Education } \\
\hline$<12$ years & $90(42.3 \%)$ & $123(57.7 \%)$ & $1.4(0.7-2.9)$ & - \\
\hline$>12$ years & $19(51.4 \%)$ & $18(48.6 \%)$ & & \\
\hline \multicolumn{5}{|l|}{ Occupation } \\
\hline Employed & $12(38.7 \%)$ & 19 (61.3\%) & $0.8(0.36-1.7)$ & - \\
\hline Unemployed & 97 (44.3\%) & $122(55.7 \%)$ & & \\
\hline \multicolumn{5}{|l|}{ Family history of DM } \\
\hline Yes & $52(46.4 \%)$ & 60 (53.6\%) & $1.2(0.75-2.04)$ & - \\
\hline No & $57(41.3 \%)$ & 81 (57.7\%) & & \\
\hline CPZeq (mg) & $432 \pm 284.3$ & $440.6 \pm 269.7$ & $1(0.9-1)$ & - \\
\hline \multicolumn{5}{|l|}{ Therapeutic Regimen } \\
\hline Monotherapy & $53(42.7 \%)$ & 71 (57.3\%) & $1.07(0.65-1.8)$ & - \\
\hline Combination & $56(44.4 \%)$ & 70 (55.6\%) & & \\
\hline \multicolumn{5}{|l|}{ Depot antipsychotic } \\
\hline Yes & $68(49.3)$ & $70(50.7 \%)$ & $1.7(1.01-2.8)$ & $1.74(0.73-4.14)$ \\
\hline No & 41 (36.6\%) & 71 (63.4\%) & & \\
\hline \multicolumn{5}{|l|}{ Olanzpine/Clozapine } \\
\hline Yes & $10(33.3 \%)$ & $20(66.7 \%)$ & $0.61(0.3-1.4)$ & - \\
\hline No & $99(45 \%)$ & $121(55 \%)$ & & \\
\hline WC (cm) & $105.1 \pm 13.2$ & $92.3 \pm 10.7$ & $1.1(1.07-1.1)$ & $1.09(1.05-1.13)$ \\
\hline Systolic BP (mmHg) & $131.1 \pm 12.9$ & $118.9 \pm 13.2$ & $1.07(1.05-1.1)$ & $1.11(1.07-1.16)$ \\
\hline Diastolic BP (mmHg) & $78.4 \pm 10.1$ & $73.2 \pm 10.9$ & $1.05(1.02-1.07)$ & $0.96(0.92-1.01)$ \\
\hline TG (mg/dl) & $256.4 \pm 224.6$ & $144.3 \pm 115.4$ & $1(1-1)$ & $1.01(1.0-1.01)$ \\
\hline HDL (mg/dl) & $42.4 \pm 11.8$ & $46.2 \pm 9.9$ & $0.96(0.94-0.99)$ & $0.95(0.91-1.00)$ \\
\hline LDL (mg/dl) & $121.7 \pm 36.8$ & $112.1 \pm 39.1$ & $1(1-1.01)$ & \\
\hline FPG (mg/dl) & $120.5 \pm 64.5$ & $83.3 \pm 13.9$ & $1.05(1.03-1.07)$ & $1.06(1.03-1.09)$ \\
\hline
\end{tabular}

Abbreviations: $S D$, Standard deviation; $O R$, Odds ratio; $C l$, confidence interval; $M S$, Metabolic syndrome; $D M$, diabetes mellitus; WC, Waist Circumference; $H D L$, Highdensity lipoprotein; $L D L$, low-density lipoprotein; $B P$, Blood pressure; $T G$, triglyceride; $F P G$, Fasting plasma glucose; $C P Z$ eq, Chlorpromazine equivalents. 
Table 4 Prevalence of metabolic dysregulations in patients with schizophrenia

\begin{tabular}{lcccccc}
\hline \multicolumn{1}{c}{ MS ATP-III A } & All Frequency (\%) & Male & Female & OR (95\% Cl) and d (Cohen's value) & P & Chi-Square value \\
\hline WC $(\mathrm{M}>102 \mathrm{~cm} ; \mathrm{F}>88 \mathrm{~cm})$ & $114(45.6 \%)$ & $58(31.9 \%)$ & $56(82.4 \%)$ & $0.1(0.05-0.2) \mathrm{d}=-1.3$ & $<0.01$ & 50.9 \\
FPG $(\geq 100 \mathrm{mg} / \mathrm{dL})$ & $80(32 \%)$ & $52(28.6 \%)$ & $28(41.2 \%)$ & $0.6(0.3-1.02) \mathrm{d}=-0.28$ & 0.06 & 3.6 \\
HDL $(\mathrm{M}<40 \mathrm{mg} / \mathrm{dl} ; \mathrm{F}<50 \mathrm{mg} / \mathrm{dl})$ & $130(52 \%)$ & $87(47.8 \%)$ & $43(63.2 \%)$ & $0.53(0.3-0.94) \mathrm{d}=-0.35$ & 0.03 & 4.7 \\
BP $(\geq 130 / 85 \mathrm{mmHg})$ & $129(51.6 \%)$ & $92(50.5 \%)$ & $31(45.6 \%)$ & $1.2(0.68-2.1) \mathrm{d}=0.1$ & 0.55 & 0.35 \\
TG $(>150 \mathrm{mg} / \mathrm{dl})$ & $123(49.2 \%)$ & $96(52.7 \%)$ & $33(48.5 \%)$ & $1.2(0.7-2.1) \mathrm{d}=0.1$ & 0.5 & 0.49 \\
\hline
\end{tabular}

Abbreviations: MS, Metabolic syndrome; ATP-III, Adult Treatment Panel III; OR, Odds ratio; $C l$, confidence interval; WC, Waist Circumference; $M$, Male; $F$, Female; HDL, High-density lipoprotein; $F P G$, Fasting plasma glucose; $B P$, Blood pressure; $T G$, triglyceride.

\section{Discussion}

In this study we investigated prevalence of MS among a sample of Arab patients with schizophrenia. We estimated that approximately $44 \%$ of the study sample has the metabolic syndrome. The high prevalence of the metabolic syndrome in the present study has several clinical implications. First, there is a crucial need to develop methods, including physical activity and nutrition, to control metabolic abnormalities among schizophrenic patients. Second, education and training are needed to ensure that mental healthcare workers have the knowledge and skills necessary to identify schizophrenic patients with the metabolic syndrome. Third, close collaboration between mental healthcare workers and other physicians is needed to establish better healthcare for patients with schizophrenia. Finally, use of antipsychotics with lesser metabolic side effects is needed in patients at risk of developing MS.

Even though there is a considerable variation in methodology and criteria among published studies, the MS prevalence in our study was within the range of prior reports published regionally and worldwide [36-42]. Studies about prevalence rate of MS obtained in the Arab world are few. A study carried out among 63 patients to determine the risk factors of metabolic syndrome in a sample of Egyptian patients with schizophrenia using the IDF criteria found that twenty four patients $(38.09 \%)$ met the criteria for MS [42]. Another study carried out among 220 UAE psychiatric inpatients using the NCEP ATP III criteria found that the prevalence of metabolic syndrome was about 48.1\% [43].

Our study showed that female patients had higher risk of having MS, which is a common finding in previous studies [36,38-41]. In a between gender comparison, a higher proportion of central obesity and low HDL-C in female patients with schizophrenia in this study was consistent with observations in the literature [38-40].

We did not find a relationship between the presence of MS and types of antipsychotic drug. The relationship between antipsychotic drugs and risk of developing MS has remained divergent in the literature $[37,41,44,45]$. Our results have found no significant difference in the antipsychotic dose measured as CPZeq or antipsychotic regimen and the presence or absence of MS. A study has reported that those receiving a combination of SGA and FGA had a higher risk of developing MS [46]. Another study showed no difference on MS profiles between patients using FGA, SGA, or combination therapy [47]. Despite the clear evidence that antipsychotic drugs are implicated in metabolic disease in patients with schizophrenia, there is increasing evidence that schizophrenia itself is an independent risk factor $[48,49]$.

It is well known that MS increases the risk of developing cardiovascular disease (CVD) and diabetes. A study has shown that metabolic syndrome accounts for up to one third of CVD in men and approximately half of new Type II diabetes mellitus over 8 years of follow-up [50]. It was suggested that CVD risk factors have an additive effect on risk for CVD, and the same statement is generally true for metabolic syndrome traits and risk for CVD and Type II DM [51]. However, Framingham model remains the most commonly validated risk model for CVD [52].

This study has three limitations. First, we enrolled subjects with stable schizophrenia state while acutely ill and more chronically sedentary patients were not included in this study which affects the generalization of the results. Second, the duration of antipsychotic drug use in this cross-sectional design was not obtained. Switching of antipsychotics is common among psychiatric patients. So the prevalence of MS between types of antipsychotics did not show significant difference. Third, factors that potentially affect the development of MS, such as lifestyle or genetic variations were not investigated.

\section{Conclusions}

In conclusion, this study indicates that the metabolic syndrome is prevalent in Arab patients with schizophrenia. Physicians treating patients with schizophrenia are recommended to monitor the components in the metabolic syndrome to identify those subjects with an increased risk for cardiovascular disorders. In addition, patient education and proper selection of antipsychotic agents are needed. 


\section{Abbreviations}

MS: Metabolic syndrome; NCEP ATPIII: National cholesterol education program adult treatment panel III; IDF: International diabetes federation; AHA/NHLBI: American heart association/national heart lung, and blood institute; ADA: American diabetes association; WC: Waist circumference; FPG: Fasting plasma glucose; HDL-C: High density lipoprotein - cholesterol; LDL-C: Low density lipoprotein - cholesterol; TC: Total cholesterol; TG: Triglycerides; BP: Blood pressure; SBP: Systolic blood pressure; DBP: Diastolic blood pressure; SGA: Second generation antipsychotics; CPZeq: Chlorpromazine equivalents; CVD: Cardiovascular disease.

\section{Competing interest}

The authors declare that they have no competing of interests.

\section{Authors' contributions}

WS: Concept, idea, literature review and manuscript writing. SZ: Statistical Analysis. SD: Data collection. SE: Data collection. AS: Concept and idea. IA: Manuscript writing. All authors read and approved the final manuscript.

\section{Acknowledgement}

The authors would like to acknowledge the staff at psychiatric clinics in North Palestine for their help in accomplishing the project.

Received: 17 August 2012 Accepted: 26 December 2012

Published: 27 December 2012

\section{References}

1. Crismon ML, Dorson PG: In Schizophrenia in Pharmacotherapy: A pathophysiologic approach. 5th edition. Edited by Dipiro J, Talbert RL, Yee G, Matzke GWells B, Posey L. New York: McGraw-Hill; 2002:1219-1242.

2. van Os J, et al: Prevalence of psychotic disorder and community level of psychotic symptoms: an urban-rural comparison. Arch Gen Psychiatry 2001, 58(7):663-668.

3. van Os J, Kapur S: Schizophrenia. Lancet 2009, 374(9690):635-645.

4. McGrath J, et al: Schizophrenia: a concise overview of incidence, prevalence, and mortality. Epidemiol Rev 2008, 30:67-76.

5. Sperling W, Biermann T: Mortality in patients with schizophrenia. Lancet 2009, 374(9701):1592. author reply 1592-3.

6. Tiihonen J, et al: 11-year follow-up of mortality in patients with schizophrenia: a population-based cohort study (FIN11 study). Lancet 2009, 374(9690):620-627.

7. Hennekens $\mathrm{CH}$ : Prevention of premature mortality among patients with schizophrenia: the need for primary prevention efforts in cardiovascular disease. CNS Spectr 2008, 13(6 Suppl 10):9-10.

8. Kelly $\mathrm{DL}$, et al: Cardiovascular disease mortality in patients with chronic schizophrenia treated with clozapine: a retrospective cohort study. J Clin Psychiatry, 71(3):304-311.

9. Citrome L: Metabolic syndrome and cardiovascular disease. J Psychopharmacol 2005, 19(6 Suppl):84-93.

10. Haffner SM, et al: Prospective analysis of the insulin-resistance syndrome (syndrome X). Diabetes 1992, 41(6):715-722

11. Sandhofer $A$, et al: Comparison of different definitions of the metabolic syndrome. Eur J Clin Invest 2007, 37(2):109-116.

12. Qiao Q: Comparison of different definitions of the metabolic syndrome in relation to cardiovascular mortality in European men and women. Diabetologia 2006, 49(12):2837-2846.

13. Golley RK, et al: Comparison of metabolic syndrome prevalence using six different definitions in overweight pre-pubertal children enrolled in a weight management study. Int J Obes (Lond) 2006, 30(5):853-860.

14. De Hert M, Peuskens B, van Winkel R: Body weight and self-esteem in patients with schizophrenia evaluated with B-WISE. Schizophr Res 2006, 88:222-226.

15. Weiden PJ, Mackell JA, McDonnell DD: Obesity as a risk factor for antipsychotic noncompliance. Schizophr Res 2004, 66(1):51-57.

16. Lyketsos CG, et al: Medical comorbidity in psychiatric inpatients: relation to clinical outcomes and hospital length of stay. Psychosomatics 2002, 43(1):24-30

17. ATPIII: Third Report of the National Cholesterol Education Program (NCEP) Expert Panel on Detection, Evaluation, and Treatment of High Blood Cholesterol in Adults (Adult Treatment Panel III) final report. Circulation 2002, 106(25):3143-3421.
18. Alberti KG, Zimmet $P$, Shaw J: The metabolic syndrome-a new worldwide definition. Lancet 2005, 366(9491):1059-1062.

19. Alberti KG, Zimmet PZ: Definition, diagnosis and classification of diabetes mellitus and its complications. Part 1: diagnosis and classification of diabetes mellitus provisional report of a WHO consultation. Diabet Med 1998, 15(7):539-553.

20. ADA: Report of the expert committee on the diagnosis and classification of diabetes mellitus. Diabetes Care 2003, 26(Suppl 1):S5-S20.

21. Grundy SM, et al: Implications of recent clinical trials for the National Cholesterol Education Program Adult Treatment Panel III Guidelines. J Am Coll Cardiol 2004, 44(3):720-732.

22. Alberti $\mathrm{KG}$, et al: Harmonizing the metabolic syndrome: a joint interim statement of the International Diabetes Federation Task Force on Epidemiology and Prevention; National Heart, Lung, and Blood Institute; American Heart Association; World Heart Federation; International Atherosclerosis Society; and International Association for the Study of Obesity. Circulation 2009, 120(16):1640-1645.

23. Cossrow N, Falkner B: Race/ethnic issues in obesity and obesity-related comorbidities. J Clin Endocrinol Metab 2004, 89(6):2590-2594.

24. Kraja AT, et al: An evaluation of the metabolic syndrome in a large multiethnic study: the Family Blood Pressure Program. Nutr Metab 2005, 2:17.

25. Rakugi H, Ogihara T: The metabolic syndrome in the asian population. Curr Hypertens Rep 2005, 7(2):103-109.

26. Abdul-Rahim HF, et al: The metabolic syndrome in the West Bank population: an urban-rural comparison. Diabetes Care 2001, 24(2):275-279.

27. Sirdah MM NA, Laham A, Abu Ghali AS: Prevalence of metabolic syndrome and associated socioeconomic and demographic factors among Palestinian adults (20-65 years) at the Gaza Strip. Diabetes Metab Syndr 2011, 5(2):93-97.

28. Yasein N, Masa'd D: Metabolic syndrome in family practice in Jordan: a study of high-risk groups. East Mediterr Health J 2011, 17(12):943-948

29. Newcomer JW: Antipsychotic medications: metabolic and cardiovascular risk. J Clin Psychiatry 2007, 68(Suppl 4):8-13.

30. Newcomer JW: Metabolic considerations in the use of antipsychotic medications: a review of recent evidence. J Clin Psychiatry 2007, 68(Suppl 1):20-27.

31. Allison DB, et al: Antipsychotic-induced weight gain: a comprehensive research synthesis. Am J Psychiatry 1999, 156(11):1686-1696.

32. Woods SW: Chlorpromazine equivalent doses for the newer atypical antipsychotics. J Clin Psychiatry 2003, 64(6):663-667.

33. Xiang YT, et al: Clinical and social correlates with the use of depot antipsychotic drugs in outpatients with schizophrenia in China. Int J Clin Pharmacol Ther 2008, 46(5):245-251.

34. Joseph D, et al: Pharmacotherapy: A pathophysiologic approach. 8th edition New York, NY: The McGraw - Hill Companies; 2011:1147-1172.

35. Chinn S: A simple method for converting an odds ratio to effect size for use in meta-analysis. Stat Med 2000, 19(22):3127-3131.

36. Cohn T, et al: Characterizing coronary heart disease risk in chronic schizophrenia: high prevalence of the metabolic syndrome. Can J Psychiatry 2004, 49(11):753-760

37. De Hert $M$, et al: Prevalence of diabetes, metabolic syndrome and metabolic abnormalities in schizophrenia over the course of the illness: a cross-sectional study. Clin Pract Epidemiol Ment Health 2006, 2:14.

38. De Hert MA, et al: Prevalence of the metabolic syndrome in patients with schizophrenia treated with antipsychotic medication. Schizophr Res 2006, 83(1):87-93.

39. Hagg S, et al: High prevalence of the metabolic syndrome among a Swedish cohort of patients with schizophrenia. Int Clin Psychopharmacol 2006, 21(2):93-98.

40. McEvoy JP, et al: Prevalence of the metabolic syndrome in patients with schizophrenia: baseline results from the Clinical Antipsychotic Trials of Intervention Effectiveness (CATIE) schizophrenia trial and comparison with national estimates from NHANES III. Schizophr Res 2005, 80(1):19-32.

41. Suvisaari JM, et al: Metabolic syndrome among persons with schizophrenia and other psychotic disorders in a general population survey. J Clin Psychiatry 2007, 68(7):1045-1055.

42. Hatata $\mathrm{H}$, et al: Risk of metabolic syndrome among Egyptian patients with schizophrenia. Current Psychiatry 2009, 16(1):85-95.

43. Shahda M, Elsayed O, El-Boraie A: Study of the prevalence of metabolic syndrome among psychiatric patients and its correlation with diagnosis and medications Egypt. J. Psychiatry 2010, 31(2):17-24. 
44. De Hert M, et al: Typical and atypical antipsychotics differentially affect long-term incidence rates of the metabolic syndrome in first-episode patients with schizophrenia: a retrospective chart review. Schizophr Res 2008, 101(1-3):295-303.

45. Meyer $\mathrm{JM}$, et al: Change in metabolic syndrome parameters with antipsychotic treatment in the CATIE Schizophrenia Trial: prospective data from phase 1. Schizophr Res 2008, 101(1-3):273-286.

46. Correll CU, et al: Does antipsychotic polypharmacy increase the risk for metabolic syndrome? Schizophr Res 2007, 89(1-3):91-100.

47. Mackin P, Watkinson HM, Young AH: Prevalence of obesity, glucose homeostasis disorders and metabolic syndrome in psychiatric patients taking typical or atypical antipsychotic drugs: a cross-sectional study. Diabetologia 2005, 48(2):215-221.

48. Thakore JH, et al: Increased visceral fat distribution in drug-naive and drug-free patients with schizophrenia. Int J Obes Relat Metab Disord 2002, 26(1):137-141.

49. Mukherjee S, Schnur DB, Reddy R: Family history of type 2 diabetes in schizophrenic patients. Lancet 1989, 1(8636):495.

50. Wilson PW, et al: Metabolic syndrome as a precursor of cardiovascular disease and type 2 diabetes mellitus. Circulation 2005, 112(20):3066-3072.

51. Wilson PW, et al: Prediction of coronary heart disease using risk factor categories. Circulation 1998, 97(18):1837-1847.

52. Matheny MM, Mc P, Glasser A: Systematic Review of Cardiovascular Disease Risk Assessment Tools [Internet]. Rockville (MD): Agency for Healthcare Research and Quality (US); 2011. (Evidence Syntheses/Technology Assessments, No. 85.) Available from: http://www.ncbi.nlm.nih.gov/books/ NBK56166/.

doi:10.1186/1471-244X-12-235

Cite this article as: Sweileh et al:: Prevalence of metabolic syndrome among patients with Schizophrenia in Palestine. BMC Psychiatry 2012 $12: 235$

\section{Submit your next manuscript to BioMed Central and take full advantage of:}

- Convenient online submission

- Thorough peer review

- No space constraints or color figure charges

- Immediate publication on acceptance

- Inclusion in PubMed, CAS, Scopus and Google Scholar

- Research which is freely available for redistribution 